\title{
Organik Kestane Kabağı Yetiştiriciliğinde Farklı Budama Uygulamalarının Verim ve Kalite Üzerine Etkisi
}

\author{
Harun Özer ${ }^{*}$ Aysun Pekşen \\ Ondokuz Mayıs Üniversitesi, Ziraat Fakültesi, Bahçe Bitkileri Bölümü, Samsun
}

Geliş tarihi (Received): 10.04.2018 Kabul tarihi (Accepted): 28.05.2018

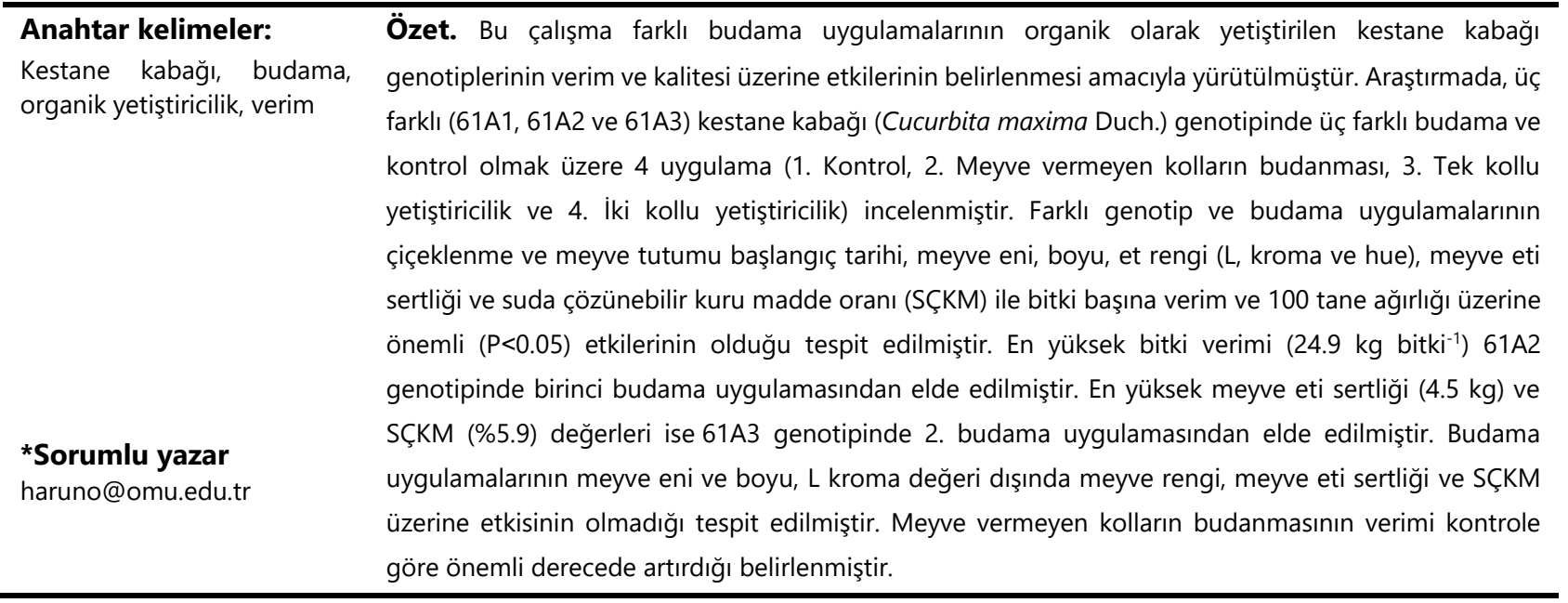

\section{Effect of Different Pruning Practices on Yield and Quality in Organic Winter Squash Cultivation}

\section{Keywords: \\ Winter squash, pruning, organic cultivation, yield}

\begin{abstract}
This study was carried out to determine the effects of different pruning practices on yield and quality of organically grown winter squash genotypes. In the study, four practices consisted of three pruning and control (1. Control, 2. Pruning of fruitless branches, 3. Single-branch growing and 4. Twobranchs growing) were investigated in 3 different winter squash (Cucurbita maxima Duch.) genotypes $(61 \mathrm{~A} 1,61 \mathrm{~A} 2$ and $61 \mathrm{~A} 3)$. It was determined that genotypes and pruning practices had significant $(P<0.05)$ effects on days to flowering and fruit set, fruit width and length, flesh color ( $L$, chroma and hue), fruit flesh firmness, soluble solids content (SSC) and also yield per plant and 100 seed weight. The highest plant yield $\left(24.9 \mathrm{~kg} \mathrm{plant}^{-1}\right)$ were obtained from the first pruning practice in $61 \mathrm{~A} 2$ genotype. The highest fruit flesh firmness $(4.5 \mathrm{~kg})$ and SSC (5.9\%) values were also obtained from the second pruning practice in 61A3 genotype. With the exception of fruit width and length, and $L$ chrome, the effects of pruning practices on fruit color, fruit flesh firmness and SSC were not significant. It was determined that the pruning practice of fruitless branches increased plant yield when compared with the control.
\end{abstract}




\section{GíRiş}

Kabakların gen merkezi Amerika kıtası kabul edilmektedir. Farklı kabak türlerinin (Cucurbita pepo, C. moschata, C. mixta ve C. maxima) bu kıtanın güneybatısı, Meksika ve Güney Amerika'nın kuzeyinde yetiştirildiğine dair arkeolojik bulgular vardır. Anavatanı olmamasına rağmen, Türkiye kışlık kabak türlerinin çeşitliliği yönünden oldukça zengin bir ülkedir (Turgut 2015). Türkiye toplam kabak üretimi 2016 yılı verilerine göre 489.9 ton olup, bunun 138.45 tonu kışlık kabaklara aittir (TUiK 2017). Cucurbita cinsi içinde yer alan kabaklar meyve boyu, şekil, dış ve iç meyve rengi bakımından önemli farklılıklar içermektedir. C. maxima (kestane kabağı), meyveleri iri (2-150 kg), kabuk rengi gümüşi-turuncu, kabuk yüzeyi dilimli veya düz, meyve kabuğu sert, meyve eti turuncu veya sarı renklidir. Türkiye'de yaygın olarak yetiştirilen kışlık kabak türleri genellikle tatlı yapımında kullanılmaktadır (Turgut 2015).

Besin içeriği bakımından insan beslenmesinde önemli bir yere sahip olan kabağın, \%6-10 civarında olan kuru maddesini büyük oranda şekerler oluşturmaktadır. Kabağın külünde \%0.03 potasyum, \%0.02 kalsiyum, \%0.1 magnezyum ve \%0.01 fosfor bulunmaktadır. Yağ oranı (\%0.4-1) oldukça az olan

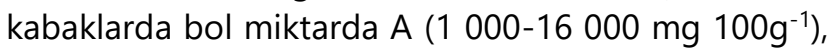
$\mathrm{B}$ (B1; $18-0.16 \mathrm{mg}$ ve B2; 0.2-0.3 mg) ve C vitamini (2875 mg) bulunmaktadır. Yapılan araştırmalarda kabak çekirdeğinin bağırsak kurdu düşürücü özelliği olup tuzsuz tüketildiğinde çok hızlı ve etkili bir şekilde tenyanın dökülmesine neden olduğu bildirilmektedir. Kabak çekirdeğinin içerdiği karotenoitlerin kalın bağırsak kanseri ve erkeklerde prostat büyüme riskini azalttığı bildirilmektedir. Ayrıca kabaktaki Omega-3 ve Omega-6 içeriğinin beyin fonksiyonlarının düzenlenmesine yardımcı olduğu ve zihinsel gelişimi olumlu yönde etkilendiği ifade edilmektedir (Turgut 2015). İnsan beslenmesinde önemli bir yere sahip kabak yetiştiriciliğinde organik tarım tekniklerinin uygulanması insan sağlığına olan faydalarının artmasını sağlayacaktır.

Organik tarımda verimlilik toprak verimliliğiyle ilişkilidir. Ancak organik yetiştiricilikte kültürel işlemlerin tekniğine uygun olarak yapılamaması da önemli ölçüde verim kayıplarına sebep olmaktadır. Terbiye sistemi ve budama uygulamaları verimi, meyve kalitesini ve bitkinin ömrünü doğrudan etkileyen kültürel işlemlerden bir tanesidir. Jarrick (1986), budama ile bitkilerin gelişimi ve veriminin değiştirilebileceğini bildirmiştir. Sebze yetiştiriciliğinde budamadan beklenen faydaları bitkinin ışıktan maksimum derecede yararlanmasını sağlamak, bitki çevresinde hava hareketini sağlamak, hastalık ve zararlılarla mücadeleyi kolaylaştırmak ve bitkilerin yeşil kalma süresini uzatmak olarak sayabiliriz (Şeniz et al., 2000; Günay 2005; Özer and Sarıbaş 2016). Yapılan çalışmalar budama işleminin bitki gelişimi, verim, kalite ve besin içeriği üzerine etkili olduğunu ortaya koymuştur (Kurtar and Abak 1996; Uygun and Sarı 2000; Şeniz et al., 2000; Özkaraman 2004; Gholipour and Nazamejad 2007; Ambroszczyk et al., 2007; Nikkhah et al., 2009; Poorbaghaiy et al., 2014; Özer and Sarıbaş 2016). Karpuz üretimini geliştirdiği için budamanın gerekli olduğu ve maksimum verim için kültürel uygulamalardan biri olarak benimsenmesi gerektiği bildirilmiştir (Oga and Umekwe 2016). Bununla birlikte yapılan çalışmalar budama uygulamalarının etkilerinin türe, çeşide ve yetiştiricilik şekline göre değişiklik gösterebildiğini ortaya koymuştur. Kışlık kabak genotiplerinin yetiştirilmesinde uygun budama tekniklerinin belirlenmesi konusundaki çalışmalar sınırlıdır. Bu çalışma, Samsun ekolojik koşullarında farklı budama uygulamalarının organik kestane kabağı yetiştiriciliğinde büyüme ve verim üzerine etkilerini belirlemek amacıyla yürütülmüştür.

\section{MATERYAL VE METOT}

Çalışma 2005 yılında Ondokuz Mayıs Üniversitesi Ziraat Fakültesi Bahçe Bitkileri Bölümü uygulama

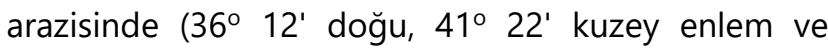
boylamları) yürütülmüştür. Denemenin yürütüldüğü arazinin toprak yapısı killi bünyede olup, $\mathrm{pH}^{\prime}$ sı nötr ve organik maddesi iyi düzeydedir.

Çalışmada Trabzon ilinin Araklı ilçesinde yerel halk tarafından yetiştiriciliği yapılan 3 adet kestane kabağı (Cucurbita maxima Duch.) genotipi kullanılmıştır. Bu genotipler plaka sistemi ile 61A1, 61A2 ve 61A3 olarak isimlendirilmiştir.

Kestane kabağı genotiplerine ait tohumların ekimi 25 Nisan tarihinde 2:1 oranında yanmış çiftlik gübresi ve bahçe toprağından oluşan harçla doldurulmuş $7 \times 7$ cm çaplı 28 gözlü viyollere yapılmıştır. Çalışmanın yapıldığı araziye dikim öncesi $3 \mathrm{~kg} \mathrm{~m}^{-2}$ hesabıyla çiftlik gübresi verilmiştir. Dikimden sonra ise bitkilere çiftlik gübresinin sulandırılmasıyla hazırlanan sıvı şerbet 30 günde bir damlama sulama sistemi ile birlikte verilmiştir. Damlama sulama sistemi $(25 \mathrm{~cm}$ 'de bir damlatıcı aralığı olan) çift sıra dikime uygun olacak şekilde yerleştirilmiştir. Kabak fideleri (dört yapraklı) arazideki masuralara sıra üzeri 200 cm, sıra arası 100 $\mathrm{cm}$ olacak şekilde 26 Mayıs tarihinde dikilmiştir.

Çalışmada yetiştiricilik periyodu boyunca 4 farklı budama uygulaması gerçekleştirilmiştir (Çizelge 1). 
Çizelge 1. Kestane kabağı yetiştiriciliğinde uygulanan farklı budama şekilleri.

Table 1. Different pruning patterns applied in winter squash cultivation.

\begin{tabular}{|c|c|c|}
\hline No & Kodu & Uygulamanın Yapılışı \\
\hline 1. & Kontrol & Budama uygulaması yapılmamıştır. \\
\hline 2. & Budama 1 & $\begin{array}{l}\text { Meyvesiz kolların çıkarılması; Meyve } \\
\text { vermeyen yan kollar ( } 8 \text { ila } 9 \text {. yaprağa } \\
\text { kadar meyve vermeyen) budanmış ve } \\
\text { meyve veren kollarda meyveden sonra } 5 \\
\text { yaprak bırakılarak uç alınmıştır. }\end{array}$ \\
\hline 3. & Budama 2 & $\begin{array}{l}\text { Tek gövdeli yetiştiricilik; Ana gövdede } 2 \\
\text { metreden sonra uç alınmış, meyve } \\
\text { vermeyen yan kollar (8 ila 9. yaprağa } \\
\text { kadar meyve vermeyen) budanmış ve } \\
\text { meyve veren kollarda meyveden sonra } 5 \\
\text { yaprak bırakılarak uç alınmıştır. }\end{array}$ \\
\hline 4. & Budama 3 & $\begin{array}{l}\text { İki gövdeli yetiştiricilik; Ana gövde } \\
\text { çıkarılarak iki kollu yetiştiricilik yapılmış, } \\
\text { bu kollar üzerinde meyve vermeyen yan } \\
\text { kollar (8 ila 9. yaprağa kadar meyve } \\
\text { vermeyen) budanmış ve meyve veren } \\
\text { kollarda meyveden sonra } 5 \text { yaprak } \\
\text { bırakılarak uçalınmıştır. }\end{array}$ \\
\hline
\end{tabular}

Bitkilerde ilk erkek ve dişi çiçeklerin açma tarihi ile oluştuğu boğum, ilk meyve tutum tarihi belirlenmiştir. Bitki başına verim değerleri, her bitkiden hasat edilen meyvelerin ağırlıkları (1 $\mathrm{g}^{\prime}$ a duyarlı hassas) terazide tartılarak $\mathrm{kg}^{\text {bitki }}{ }^{-1}$ olarak belirlenmiştir. Her bir genotipe ait uygulamada meyve eni ve boyu $(\mathrm{cm})$ saptanmıştır. Ayrıca meyve et rengi değerleri renk ölçüm aleti ile L, kroma ve hue olarak, meyve eti sertliği penetrometre yardımıyla kg olarak ve suda çözünebilir kuru madde el refraktometresi ile \% olarak belirlenmiştir. Ayrıca meyve başına tohum verimi ( $g$ ) ve $1 \mathrm{~g}$ 'daki tohum sayısı (adet) tespit edilmiştir.

Araştırma, Tesadüf Parselleri Deneme Desenine göre 3 tekerrürlü ve her tekerrürde 9 bitki olacak şekilde kurulmuştur. Çalışma sonucunda elde edilen verilerin değerlendirilmesinde SPSS 17.0 istatistik analiz programı kullanılmıştır. Elde edilen ortalamalar arasındaki farklar Duncan çoklu karşılaştırma testiyle $(P<0.05)$ belirlenmiştir.

\section{BULGULAR VE TARTIŞMA}

Çalışmada kestane kabağı genotiplerinde farkı budama uygulamalarının ilk çiçeklenme (erkek ve dişi), ilk dişi çiçeğin oluştuğu boğum sayısı ve ilk meyve tutumu üzerine önemli $(P<0.05)$ etkileri olduğu belirlenmiştir. Kestane kabağı genotiplerinde farklı budama uygulamalarının erkek çiçeğin oluştuğu boğum sayısı üzerine istatistiki olarak etkisinin ise önemli olmadığı belirlenmiştir. Budamalar ortalaması incelendiğinde kontrol uygulamasının ilk erkek çiçeklerin açma tarihi dışında ilk dişi çiçeklenme ve meyve tutum tarihleri ile erkek çiçeklerin oluştuğu boğum sayıları bakımından diğer budama uygulamalarına göre istatistiksel olarak önemli derecede farklı olduğu belirlenmiştir. Illk çiçeklenme ve oluşan boğum sayıları dikkate alındığında budama uygulamaları ile erkencilik sağlanamamıştır (Çizelge 2).

Kestane kabağı genotiplerinin ilk erkek ve dişi çiçek oluşum tarihlerinin belirlendiği çalışmada erkek çiçeklerin 71-72 günde, dişi çiçeklerin 73-74 günde oluştuğu bildirilmiştir (Balkaya et al., 2011). Bu çalışmada ise ilk erkek çiçekler 25.1-30.0 gün ve dişi çiçekler 34.4-47 günde oluşmuştur (Çizelge 2). Bu durumun çalışmada kullanılan genotiplerin ve ekolojilerin farklı olmasından kaynaklandığı düşünülmektedir.

Kestane kabağı genotiplerinde farklı budama uygulamalarının meyve boyu, eni ve et rengi değerleri üzerine istatistiki olarak önemli $(P<0.05)$ etkileri belirlenmiştir. Genotip budama interaksiyonu yönünden incelediğimizde meyve eni $22.0-34.5 \mathrm{~cm}$ ve meyve boyu ise $24.0-46.0 \mathrm{~cm}$ olarak tespit edilmiştir Meyve et rengi değerleri bakımından en yüksek $L$ (77.2), kroma (99.9) ve hue (5.27) değeri 61A1 genotipinde 2 . budama uygulamasından elde edilmiştir. Bunu aralarında istatistiksel fark bulunmayan $61 \mathrm{~A} 1$ genotipinde 3 . budama ve $61 \mathrm{~A} 2$ genotipinde kontrol uygulamasından elde edilen meyvelerin et renkleri izlemiştir.

Çalışmada budama uygulamalarının sadece meyve et renginden $L$ üzerine etki ettiği, meyve eni ve boyu ile meyve et renginde kroma ve hue değerleri üzerine etkisinin önemli olmadığı saptanmıştır. En yüksek L (55.61) değeri 2. budama uygulamasında belirlenmiştir (Çizelge 3).

Kestane kabağı genotiplerinin bazı özelliklerinin incelendiği çalışmada meyve boyu değerlerinin 35.8$38.4 \mathrm{~cm}$, meyve eninin 41.5-46.5 cm değerleri arasında değiştiği bildirilmiştir (Balkaya et al., 2011). Bu çalışmada meyve boyu ve eni değerlerinin daha düşük olması bitkilerin organik yetiştirilmesinden kaynaklanan besin elementi eksikliğinden kaynaklanmış olduğu düşünülmektedir. Balkaya et al. (2011) yürüttüğü çalışmada meyve rengi değerlerinden $L$ değerinin 48.95 ile 58.64 arasında değiştiği ifade edilmiştir. Bu çalışmada da benzer sonuçlar elde edilmekle birlikte 3 . budama uygulamasındaki meyvelerin daha parlak olduğu belirlenmiştir (Çizelge 3). Yanmaz et al. (2016), kestane kabağı genotiplerinin L değerlerinin 56.89-80.84, hue değerlerinin 2.06-12.62 ve kroma değerlerinin 28.8274.13 arasında değiştiğini bildirmişlerdir.

Çalışmada meyve eti sertliği, SÇKM, verim, tohum verimi ve $1 \mathrm{~g}$ 'daki tohum sayısı yönünden genotipx budama interaksiyonu incelendiğinde istatistiki olarak 
önemli $\quad(P<0.05) \quad$ farklılıklar belirlenmiştir. En yüksek meyve eti sertliği (4.5 kg) ve SÇKM (\%5.9) değerleri $61 \mathrm{A3}$ genotipinde 2 . budama uygulamasında belirlenmiştir (Çizelge 4). Bu çalışmada elde edilen meyve eti sertliği değerlerinin Balkaya et al. (2011)'nın elde ettiği meyve eti sertliği değerlerinden daha yüksek, buna karşılık SÇKM değerlerinden daha düşük olduğu belirlenmiştir.

Çizelge 3. Farklı budama uygulamalarının kestane kabağı yetiştiriciliğinde meyve boyu, eni ve rengi üzerine etkisi.

Table 3. Effect of different pruning practices on fruit shape and fruit color in winter squash.

\begin{tabular}{|c|c|c|c|c|c|c|}
\hline \multirow[b]{2}{*}{ Genotipler } & \multirow[b]{2}{*}{ Uygulamalar } & \multicolumn{2}{|c|}{ Meyve } & \multicolumn{3}{|c|}{ Meyve et rengi } \\
\hline & & Boy $(\mathrm{cm})$ & En $(\mathrm{cm})$ & $\mathbf{L}$ & Kroma & Hue \\
\hline \multirow{4}{*}{$61 \mathrm{~A} 1$} & Kontrol & $28.1 b^{*}$ & $25.5 b^{*}$ & $54.7 b^{*}$ & $91.1 \mathrm{ab}^{*}$ & $0.08(-) c^{*}$ \\
\hline & Budama 1 & $30.0 \mathrm{~b}$ & $26.0 \mathrm{~b}$ & $56.5 \mathrm{~b}$ & $84.2 \mathrm{ab}$ & $1.85(+) b$ \\
\hline & Budama 2 & $24.0 \mathrm{c}$ & $24.0 \mathrm{c}$ & $77.2 \mathrm{a}$ & 99.9 a & $5.27(-) \mathrm{a}$ \\
\hline & Budama 3 & $26.5 c$ & $22.0 \mathrm{c}$ & $71.0 \mathrm{a}$ & $98.4 \mathrm{a}$ & $0.73(-) c$ \\
\hline \multirow[t]{4}{*}{$61 \mathrm{~A} 2$} & Kontrol & $40.8 \mathrm{a}$ & $34.4 \mathrm{a}$ & $63.7 \mathrm{a}$ & $77.0 \mathrm{ab}$ & $0.17(+) \mathrm{c}$ \\
\hline & Budama 1 & $40.6 \mathrm{a}$ & 33.5 a & $51.3 b$ & $81.8 \mathrm{ab}$ & $0.61(+) c$ \\
\hline & Budama 2 & $46.0 \mathrm{a}$ & $28.6 \mathrm{~b}$ & $51.6 \mathrm{~b}$ & $75.8 \mathrm{ab}$ & $1.49(+) b$ \\
\hline & Budama 3 & $43.5 \mathrm{a}$ & $34.5 \mathrm{a}$ & $45.9 c$ & $78.6 \mathrm{ab}$ & $0.98(+) c$ \\
\hline \multirow[t]{4}{*}{$61 \mathrm{A3}$} & Kontrol & $31.4 b$ & $30.8 \mathrm{a}$ & $41.5 \mathrm{c}$ & $71.4 \mathrm{ab}$ & $3.27(-) a b$ \\
\hline & Budama 1 & $29.0 \mathrm{~b}$ & $25.7 \mathrm{~b}$ & $39.6 c$ & $68.3 \mathrm{~b}$ & $1.39(-) b$ \\
\hline & Budama 2 & $27.0 \mathrm{~b}$ & $25.3 b$ & $38.0 \mathrm{c}$ & $65.7 \mathrm{~b}$ & $0.26(+) c$ \\
\hline & Budama 3 & $27.3 \mathrm{~b}$ & $24.7 \mathrm{c}$ & $41.9 \mathrm{c}$ & $72.3 \mathrm{ab}$ & $0.13(-) c$ \\
\hline \multicolumn{7}{|c|}{ Budamalar ortalaması } \\
\hline Kontrol & & 30.3 & 33.5 & $53.32 b^{*}$ & 79.85 & $1.06(-)$ \\
\hline Budama 1 & & 28.4 & 33.2 & $49.16 \mathrm{c}$ & 78.11 & $0.35(-)$ \\
\hline Budama 2 & & 26.0 & 32.3 & $55.61 \mathrm{a}$ & 80.52 & $1.17(-)$ \\
\hline Budama 3 & & 27.1 & 32.4 & $52.96 \mathrm{~b}$ & 83.09 & $0.04(+)$ \\
\hline
\end{tabular}

*P<0.05 düzeyinde önemli.

Çizelge 4. Farklı budama uygulamalarının kestane kabağı yetiştiriciliğinde uygulanan meyve eti sertliği, SÇKM, verim, tohum verimi ve $1 \mathrm{~g}$ 'daki tohum sayısı üzerine etkisi.

Table 4. Effect of different pruning practices on fruit firmness, SSC, yield, seed yield and number of seeds per $1 \mathrm{~g}$ applied in winter squash.

\begin{tabular}{|c|c|c|c|c|c|c|}
\hline Genotipler & Uygulamalar & $\begin{array}{l}\text { Meyve eti } \\
\text { sertlik (kg) }\end{array}$ & $\begin{array}{c}\text { SÇKM } \\
\text { (\%) }\end{array}$ & $\begin{array}{c}\text { Verim } \\
\left(\mathrm{kg} \mathrm{bitki}^{-1}\right)\end{array}$ & $\begin{array}{c}\text { Tohum verimi } \\
\left(\text { g meyve }^{-1}\right)\end{array}$ & $\begin{array}{l}1 \text { g'daki tohum } \\
\text { sayısı (adet) }\end{array}$ \\
\hline \multirow[t]{4}{*}{ 61A1 } & Kontrol & $4.1 \mathrm{ab}^{\star}$ & $4.7 a b^{*}$ & $10.36 \mathrm{e}^{\star}$ & $86.07 c^{*}$ & $2.8 \mathrm{ab}^{\star}$ \\
\hline & Budama 1 & $3.9 \mathrm{~b}$ & $4.9 \mathrm{ab}$ & $9.44 \mathrm{e}$ & $155.09 a b$ & $2.1 \mathrm{c}$ \\
\hline & Budama 2 & $4.1 \mathrm{ab}$ & $5.1 \mathrm{ab}$ & $9.23 \mathrm{e}$ & $105.53 \mathrm{~b}$ & $3.5 \mathrm{a}$ \\
\hline & Budama 3 & $3.7 \mathrm{~b}$ & $3.8 \mathrm{~b}$ & $9.92 \mathrm{e}$ & $106.16 \mathrm{~b}$ & $1.9 \mathrm{c}$ \\
\hline \multirow[t]{4}{*}{$61 \mathrm{~A} 2$} & Kontrol & $3.7 \mathrm{~b}$ & $3.2 \mathrm{~b}$ & $20.46 c$ & $113.95 b$ & $2.3 \mathrm{~b}$ \\
\hline & Budama 1 & $3.5 \mathrm{c}$ & $3.3 \mathrm{~b}$ & $24.89 \mathrm{a}$ & $116.63 \mathrm{~b}$ & $2.2 \mathrm{bc}$ \\
\hline & Budama 2 & $3.4 \mathrm{c}$ & $2.9 \mathrm{c}$ & $18.93 \mathrm{~d}$ & $173.00 \mathrm{a}$ & $2.4 \mathrm{~b}$ \\
\hline & Budama 3 & $3.6 \mathrm{~b}$ & $3.3 \mathrm{~b}$ & $23.59 \mathrm{~b}$ & $99.29 \mathrm{c}$ & $2.8 \mathrm{ab}$ \\
\hline \multirow[t]{4}{*}{$61 \mathrm{A3}$} & Kontrol & $4.2 \mathrm{ab}$ & $4.9 \mathrm{ab}$ & $11.82 \mathrm{e}$ & $143.19 \mathrm{ab}$ & $2.5 \mathrm{~b}$ \\
\hline & Budama 1 & $4.3 \mathrm{ab}$ & $4.3 \mathrm{ab}$ & $11.04 \mathrm{e}$ & $120.58 \mathrm{ab}$ & $2.3 \mathrm{~b}$ \\
\hline & Budama 2 & $4.5 \mathrm{a}$ & $5.9 \mathrm{a}$ & $10.62 \mathrm{e}$ & $140.32 a b$ & $2.2 b c$ \\
\hline & Budama 3 & $4.2 \mathrm{ab}$ & $4.9 \mathrm{ab}$ & $10.73 \mathrm{e}$ & $117.19 \mathrm{~b}$ & $2.9 \mathrm{ab}$ \\
\hline \multicolumn{7}{|c|}{ Budamalar ortalaması } \\
\hline Kontrol & & 3.99 & 4.24 & $14.22 \mathrm{~b}$ & $114.40 \mathrm{~b}$ & 2.56 \\
\hline Budama 1 & & 3.91 & 4.20 & $15.12 \mathrm{a}$ & $130.77 \mathrm{a}$ & 2.16 \\
\hline Budama 2 & & 3.99 & 4.60 & $12.93 \mathrm{c}$ & 139.62 a & 2.71 \\
\hline Budama 3 & & 3.83 & 4.03 & $14.75 \mathrm{~b}$ & $107.55 \mathrm{~b}$ & 2.57 \\
\hline
\end{tabular}

${ }^{*} \mathrm{P}<0.05$ düzeyinde önemli. 
Budama ortalamaları incelendiğinde budamanın sadece verim ve tohum verimi üzerine etkileri önemli $(P<0.05)$ bulunmuştur. En yüksek verim $15.12 \mathrm{~kg}$ ile 1. budama uygulamasından, tohum verimi ise aralarında istatistiksel fark bulunmayan sırasıyla 139.62 ve 130.77 g meyve ${ }^{-1}$ ile 2 . ve 1 . budama uygulamasından elde edilmiştir (Çizelge 4). Çalışmada bitki başına verim değerleri $9.23-24.89 \mathrm{~kg} \mathrm{bitki}^{-1}$ arasında bulunmuş olup, bitki başına verim değerlerinin $8.59-26.46 \mathrm{~kg} \mathrm{bitki}^{-1}$ arasında değiştiğini bildiren Balkaya et al. (2008)'nın bulguları ile benzer olduğu belirlenmiştir. Buna karşılık budama uygulaması sayesinde dekardaki bitki sayısının artmasından dolayı dekara verim değerleri (6.463-7.562 $\left.\mathrm{kg} \mathrm{da}^{-1}\right)$, bazı yerel kestane kabağı tiplerinin verim değerlerinin $1.825-2.418 \mathrm{~kg} \mathrm{da}^{-1}$ arasında değiştiğini bildiren Sezer et al. (1993)'a göre daha yüksek bulunmuştur. Budama vejetatif gelişmeyi sınırlamakta, nüfuz eden ışık miktarı ve fotosentez etkinliğini artırmasına bağlı olarak ortalama meyve ağırlığını ve erkenci meyve verimini artırmaktadır (Preece and Read 2005). Goda et al. (2014) budama uygulamalarının vejetatif gelişme parametrelerini ve meyvenin fiziksel ve kimyasal özelliklerini geliştirdiği ve meyve verimini artırdığını bildirmişlerdir.

En yüksek tohum verimi ( $173 \mathrm{~g}) 61 \mathrm{~A} 2$ genotipinde 2. budama uygulamasından, $1 \mathrm{~g}$ 'daki tohum sayısı ise $3.5 \mathrm{~g}$ ile 61A1 genotipinde 2. budama uygulamasında tespit edilmiştir (Çizelge 3). Elde edilen tohum verim değerleri Balkaya et al. (2011) tarafından yürütülen çalışmadaki genotiplerin tohum verimi değerleri ile benzerlik göstermiştir.

\section{SONUÇ}

Kestane kabağı (Cucurbita maxima Duch.) kuvvetli kök yapısı ve özellikle abiyotik stres koşullarına karşı dayanımı yüksek olması nedeniyle toprak üstü aksamı hızıı büyüyen bir bitkidir. Bu özelliği sebebiyle dikim mesafeleri uzun tutulmaktadır. Bu durum metrekareye düşen bitki sayısını azalmaktadır. Metre kareye düşen bitki sayısını artırmak ve dolayısıyla verimi artırmak için ıslah çalışmaları yapılabilir. Ancak, budama uygulamalarıyla da dikim mesafesi ayarlanarak verim artışı sağlanabilir. Bu çalışma sonucunda budama ile kontrole göre verim artışı sağlanabileceği belirlenmiştir. Kabakta verim ve kaliteyi artırmak amacıyla daha detaylı budama çalışmalarına intiyaç bulunmaktadır.

\section{KAYNAKLAR}

Ambroszczyk AM., Cebula S and Sekara A., 2007. The effect of plant pruning on yield and fruit quality of eggplant (Solanum melongena L.) in greenhouse cultivation. Horticulture, Environment, and Biotechnology, 48(5): 277-285.
Balkaya A., Kurtar SE., Yanmaz R and Özbakır M., 2008. Karadeniz bölgesi'nde kışlık kabak türlerinde (Kestane kabağı Cucurbita maxima Duchesne ve Balkabağ Cucurbita moschata Duchesne) gen kaynaklarının toplanması, karakterizasyonu ve değerlendirilmesi. тÜBіTAK TOVAG Proje 1040144, 1-178.

Balkaya A., Kurtar ES., Yanmaz R and Özbakır M., 2011. Karadeniz Bölgesi kestane kabağı (Cucurbita maxima) popülasyonlarından seleksiyon ıslahı yoluyla geliştirilen çeşit adayları. Türkiye IV. Tohumculuk Kongresi, 14-17 Haziran, Samsun.

Gholipour A and Nazarnejad H., 2007. The effect of stem pruning and nitrogen levels of on some physicochemical characteristics of pumpkin seed (Cucurbita pepo L.). Pakistan Journal of Biological Sciences, 10(20): 3726-9.

Goda Y., Helaly AA., Abd El-Rehim AS., Mohamed AA and ElZeiny OAH., 2014. Effect of pruning on growth, yield and fruit quality of husk tomato (Physalis pubescens L.). Journal of American Science, 10(1): 5-10.

Günay A., 2005. Sebze Yetiştiriciliği, Cilt-II, Meta Basımevi, İzmir.

Jarrick J., 1986. Training and Pruning. Horticulture Science.

Kurtar ES and Abak K. 1996. Alçak tünelde kavun yetiştiriciliğinde malçın ve değişik budama şekillerinin erkencilik, verim ve kalite üzerine etkisi. Ondokuz Mayıs Üniversitesi Ziraat Fakültesi Dergisi, 11(2): 101-116.

Nikkhah BR., Khodadadi M., Piry Pirivatlo S and Hassanpanah D., 2009. The effects of planting methods and head pruning on seed yield and yield components of medicinal pumpkin (Cucurbita pepo subsp. pepo convar. pepo var styriaca) at low temperature areas. Pakistan Journal of Biological Sciences, 12(6): 538-541.

Oga IO and Umekwe PN., 2016. Effects of pruning and plant spacing on the growth and yield of watermelon (Citrullus lanatus L.) in Unwana-Afikpo. International Journal of Science and Research, 5(4): 110-115.

Özer H and Sarıbaş HŞ., 2016. Organik patlıcan yetiştiriciliğinde farklı budama sistemlerinin büyüme ve verime etkisi. Bahçe(Özel Sayı), 45(2): 81-85.

Özkaraman F., 2004. Sera Koşullarında Sıcaklık, Işık ve Farklı Budamaların Kavunda (Cucumis melon L.) Büyüme, Gelişme ve Verim Üzerine Kantitatif Etkileri. Doktora Tezi, Ondokuz Mayıs Üniversitesi Fen Bilimleri Enstitüsü, Samsun.

Poorbaghaiy KSA., Pouryousef M., Jamshidi K and Azimi MR., 2014. Effects of plant density and main stem pruning of head on yield and its components of pumpkin (Cucurbita pepocon var. pepo var. Styriaca). Iranian Journal of Medicinal and Aromatic Plants, 30(1): 1-9.

Preece JE and Read PE., 2005. The Biology of Horticulture. $2^{\text {th }}$ Ed., Copyright by John Wiley and Sons, New York, United States. 
Sezer A., Uzun S., Üner A and Odabaş F., 1993. Bazı mahalli kestane kabağı (Cucurbita maxima Duch.) tiplerinin Samsun şartlarına adaptasyonu ve başlıca özellikleri üzerinde bir araştırma. Ondokuz Mayıs Üniversitesi Ziraat Fakültesi Dergisi, 1: 100-113.

Şeniz V., Demirel F and Akbudak N., 2000. Serada yetiştirilen hıyar çeşitlerinde uygulanan budama sisteminin verim ve kaliteye etkisi. III. Sebze Tarımı Sempozyumu, 11-13 Eylül, Isparta.

TUIK 2017. Bitkisel üretim istatistikleri. http://www._tuik.gov. tr/PreTablo.do?alt_id=1001 [6 Kasım, 2017].
Turgut G., 2015. Çerezlik Kabak Genotiplerinin Erzurum Şartlarında Adaptasyonu, Verim ve Kalitelerinin Belirlenmesi. Yüksek Lisans Tezi, Atatürk Ünivesitesi Fen Bilimleri Enstitüsü, Erzurum.

Uygun N and Sarı N., 2000. Sera kavun yetiştiriciliğinde farklı budama yöntemleri ile meyve bağlatma yüksekliğinin bitki gelişimi, verim ve meyve özellikleri üzerine etkileri. Turkish Journal of Agriculture and Forestry, 24: 365-373.

Yanmaz R., Akan S and Salman A., 2016. Türkiye'den toplanan kestane kabağı (Cucurbita maxima Duchesne) genotiplerinde meyve et rengi ile karotenoid miktarı arasındaki ilişkinin belirlenmesi. Bahçe(Özel sayı), 45(2): 55-60. 